\title{
CAMA
}

Centre for Applied Macroeconomic Analysis

\section{American Business Cycles 1889-1913: An Accounting Approach}

\section{CAMA Working Paper 6/2021 January 2021}

Dou Jiang

Nanjing University of Finance and Economics

Mark Weder

Aarhus University

Centre for Applied Macroeconomic Analysis, ANU

\section{Abstract}

This paper quantitatively investigates the Depression of the 1890s and the 1907 recession in the United States. Business Cycle Accounting decomposes economic fluctuations into their contributing factors. The results suggest that both the 1890s and the 1907 recessions were primarily caused by factors that affect the efficiency wedge, i.e. slumps in the economy's factor productivity. Distortions to the labor wedge played a less important role. Models with financial market frictions that translate into the efficiency wedge are the most promising candidates for explaining the recessionary episodes. 


\title{
Keywords
}

Business cycles, Depression of the 1890s, Recession of 1907

\author{
JEL Classification
}

E32, E44, N11

\section{Address for correspondence:}

(E) cama.admin@anu.edu.au

ISSN 2206-0332

The Centre for Applied Macroeconomic Analysis in the Crawford School of Public Policy has been established to build strong links between professional macroeconomists. It provides a forum for quality macroeconomic research and discussion of policy issues between academia, government and the private sector.

The Crawford School of Public Policy is the Australian National University's public policy school, serving and influencing Australia, Asia and the Pacific through advanced policy research, graduate and executive education, and policy impact. 


\title{
American Business Cycles 1889-1913: An Accounting Approach*
}

\author{
Dou Jiang \\ Nanjing University of Finance and Economics \\ Mark Weder ${ }^{\dagger}$ \\ Aarhus University and CAMA
}

December 24, 2020

\begin{abstract}
This paper quantitatively investigates the Depression of the 1890s and the 1907 recession in the United States. Business Cycle Accounting decomposes economic fluctuations into their contributing factors. The results suggest that both the 1890s and the 1907 recessions were primarily caused by factors that affect the efficiency wedge, i.e. slumps in the economy's factor productivity. Distortions to the labor wedge played a less important role. Models with financial market frictions that translate into the efficiency wedge are the most promising candidates for explaining the recessionary episodes.
\end{abstract}

${ }^{*}$ We would like to thank two insightful, constructive and anonymous referees and an editor of this Journal for excellent comments. Weder acknowledges generous support from the Australian Research Council, under the grant DP140102869 and would like to thank the Bank of Finland for its hospitality and for providing an excellent research environment. Keywords: Business cycles, Depression of the 1890s, Recession of 1907. JEL classification: E32, E44, N11.

${ }^{\dagger}$ Weder is a Research Associate with CAMA. mweder@econ.au.dk. 


\section{Introduction}

The string of economic slumps in the United States, beginning in 1890 and leading up all the way to World War I, has received limited attention from macroeconomists, likely because of being overshadowed by the Great Depression and, as of late, the Great Recession. However, several striking similarities stand out between these earlier slumps and the Great Depression and Recession. To start with, in all cases, the crises appeared to have originated within the financial sector that then spread through the rest of the economy. Also, all slumps coincide with panics on financial markets associated with rapid price declines on asset markets. Lastly, during all these episodes, the recoveries were exceptionally tepid.

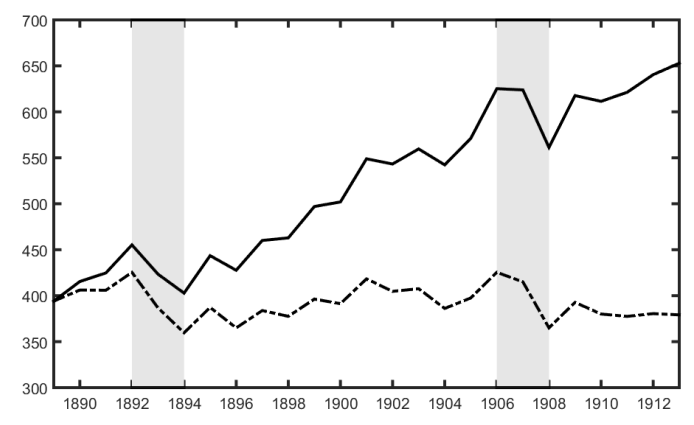

Figure 1: Real GNP per Capita in 1889-1913.

The period from 1863 to 1914, the National Banking Era, was characterized by the absence of a central bank. While financial regulation existed and clearinghouses took on roles later fulfilled by the Federal Reserve, these regulations and arrangements were uneven across States and often inadequate and ineffective in dealing with crisis events. ${ }^{1}$ Paired with the limited role played by fiscal policies the National Banking Era provides an useful laboratory for studying recessions. Although the various specifics of the economic environment and circumstances dif-

\footnotetext{
${ }^{1}$ See the excellent exposition in Gorton and Tallman (2018).
} 
fer from today's economy, we believe that macroeconomics can potentially learn valuable lessons from studying these historic slumps. In particular, we concentrate on two macroeconomic events: the panics and slumps of 1893 and 1907 which together with the Great Depression and the 1920-21 recession make up the list of the largest recessions in the United States. The current paper is a first approach towards these early recessions working with quantitative dynamic general equilibrium theory and by conducting Business Cycle Accounting (BCA) measurements it will provide directions for future research. ${ }^{2} \mathrm{BCA}$ a) isolates promising classes of models and theories and b) guides the development of theory. The approach sets up a prototype model with time-varying wedges for which, as Chari et al. (2007) and Brinca et al. (2016) demonstrate, mappings exists between the prototype and detailed models with frictions. The core is the accounting procedure involves data to measure wedges, to estimate stochastic processes and to indicate how much of macroeconomic fluctuations are accounted for by each wedge.

\subsection{Setting the scene}

The 1890s were a tumultuous period for the U.S. macroeconomy. The National Bureau of Economic Research dates four recessions for this decade: 1890:III1891:II, 1893:I-1894:II, 1895:IV-1897:II and 1899:III-1900:IV. Thus, the Depression of the Nineties (Hoffmann, 1956, 1970) looks rather like a sequence of recessions. Of these, the contraction beginning in early 1893 was the hardest and the economy's full recovery was painfully slow. To put this into perspective, per capita output dipped by over 15 percent from its peak and the cumulative economic costs were enormous: it was only by 1901 that the U.S. economy again reached aggregate trend-output. Lebergott (1964) estimates the unemployment rate for

\footnotetext{
${ }^{2}$ Work applying modern macroeconomic models to this historical episode seems very limited. To our knowledge, the studies by Kehoe and Prescott (2008) and Harrison and Weder (2009) come closest by going back to 1919. Pensieroso (2011) and Bridji (2013) are other applications of BCA to a historical crises.
} 
1894 at 18 percent. More recessions followed in 1902:IV-1904:III, 1907:II-1908:II, 1910:I-19012:IV and 1913:I-1914:IV. The recession in 1907 was one of the largest during the National Banking Era and, eventually, its repercussions led to the establishment of the Federal Reserve System. Figure 1 visualizes these fluctuations in undetrended and linearly-detrended real gross national product per capita forms. ${ }^{3}$

Explanations for the depression state of the 1890s abound and range from overproduction that carried over from the Second Industrial Revolution (Glasner et al., 1997), financial disruptions to devaluations in the form of shifting from a gold to a silver standard (Temin, 1998). The recession of 1907 is often regarded as a story of a banking panic (Tallman, 2012). Although many economists agree about primitive causes of these economic recessions, the propagation mechanisms through which they lead to economic downturns remain more open. This paper establishes guidance on theoretical modelling of the pre-Fed U.S. economy.

\subsection{What we do}

In this paper, we put to use BCA introduced by Chari et al. (2007) and further elaborated in Brinca et al. (2016) to decompose economic fluctuations into their contributing factors and, to our knowledge, the current study is the first such that addresses these early recessions in the context of dynamic general equilibrium framework. ${ }^{4}$ We shed light on the most promising propagation channels for business fluctuations during this period. Using the BCA technique, we first measure the deviations of the real world economic behavior from its first-best outcome implied by the standard growth model to then pin down the deviations or wedges:

- the efficiency wedge - measured as time-varying productivity and isomorphic to a total factor productivity shock

\footnotetext{
${ }^{3}$ Our data are annual and from Kendrick (1961). To organize our presentation, we focus on the period of 1892-1894 as the most severe economic downturns during the 1890 s occur in these years. We also emphasize the big economic slumps from 1906 to 1908.

${ }^{4}$ Nason and Tallman's (2015) study of credit and demand shocks puts to use a MS-BVAR model that includes the $1890 \mathrm{~s}$.
} 
- the labor wedge - a wedge between the marginal product of labor and the marginal rate of substitution between consumption and leisure. It is isomorphic to distortionary tax rates on labor income

- the investment wedge - a distortion to the Euler equation. The wedges at face value is isomorphic to a tax on investment

- the government consumption wedge - defined as the sum of government spending and net export. The wedge is the residual output component not explained by consumption or investment.

In a second step, the artificial economy is simulated using different scenarios in which only one wedge (or a subset) varies over time. Such counterfactuals allow to evaluate the relative importance of each wedge. Lastly, we evaluate relevant economics during the period that may explain the variations of the main wedges identified earlier.

To organize the presentation, we divide our analysis into two subperiods: 18891901 and 1901-1913. For both periods, the efficiency wedge is identified to be of prime importance and the labor wedge also playing a non-negligible role. The equivalence results of Chari et al. (2007) together with the diagnostic results provide an a priori guidance for researchers of the era: future work should focus on models with frictions that could manifest themselves as the efficiency wedge. After reviewing the historical narrative and evidence, the efficiency wedge seems associated with time-variant degrees of financial distress. The labor wedge appears to cover some role however, the other two wedges appear to be less important.

\section{Business cycle accounting}

In this section, we describe the prototype model used in BCA. As most modern dynamic macroeconomic models it has at its core a prototypical real business cycle 
model. This model incorporates four stochastic wedges: the efficiency wedge, the labor wedge, the investment wedge, and the government consumption wedge. The four measures can be thought of as capturing distortions to perfectly competitive markets settings.

\subsection{People and firms}

The economy consists of identical infinitely-lived households who are endowed with one unit of time in each period. They choose per capita consumption $c_{t}$, the supply of labor service $h_{t}$ and per capita physical capital $k_{t+1}$, taking the rental rate $r_{t}$ and real wages $w_{t}$ as given. Firms produce goods using capital and labor services to maximize their profits. Households own the firms and therefore any profits are remitted to households. Time is discrete and begins in $t=0$. The population grows at a constant rate $n$ and the deterministic rate of technological progress is given by $\gamma$. Formally, a representative household maximizes the present discounted value of lifetime utility

$$
\max _{c_{t}, h_{t}, k_{t+1}} E_{0} \sum_{t=0}^{\infty} \beta^{t}(1+n)^{t} u\left(c_{t}, 1-h_{t}\right) \quad 0<\beta<1
$$

subject to the budget constraint

$$
c_{t}+\left(1+\tau_{x t}\right) x_{t}=\left(1-\tau_{h t}\right) w_{t} h_{t}+r_{t} k_{t}
$$

in which $x_{t}$ is per capita investment in new capital and $\beta$ is the discount factor parameter. The household's period utility is represented by

$$
u\left(c_{t}, 1-h_{t}\right)=\log c_{t}+\theta \log \left(1-h_{t}\right) \quad \theta>0
$$

where $\theta$ measures the disutility of working. The economy has four exogenous shock variables. At face value the labor wedge and investment wedge behave like taxes levied on people's labor income and investment spending. The measure of the labor wedge and investment wedge are given by $1-\tau_{h t}$ and $1 /\left(1+\tau_{x t}\right)$. These 
wedges, akin to taxes, distort the agent's first order conditions and prevent the economy from its best outcome. In the absence of market frictions, the value of these wedges should be equal to one. Given the depreciation rate $\delta$, the law of motion for capital accumulation is given by

$$
(1+\gamma)(1+n) k_{t+1}=(1-\delta) k_{t}+x_{t} \quad 0<\delta<1
$$

The representative firm's problem is to maximize its profit subject to its technology

$$
\max _{k_{t}, h_{t}} y_{t}-r_{t} k_{t}-w_{t} h_{t}
$$

The firms have access to a Cobb-Douglas technology

$$
y=k_{t}^{\alpha}\left(z_{t} h_{t}\right)^{1-\alpha} \quad 0<\alpha<1
$$

where $z_{t}^{1-\alpha}$ captures the efficiency wedge. Factor markets are perfectly competitive.

\subsection{Equilibrium}

The equilibrium in this economy is defined as a set of prices $\left\{r_{t}, w_{t}\right\}_{t=0}^{\infty}$ and a set of allocations $\left\{c_{t}, h_{t}, k_{t}, x_{t}, y_{t}\right\}_{t=0}^{\infty}$ satisfying households' and firms' first order conditions as well as the economy's constraints including initial and transversality conditions. Therefore the economy can be summarized by the following equilibrium equations

$$
\begin{gathered}
\frac{\theta c_{t}}{1-h_{t}}=\frac{\left(1-\tau_{h t}\right)(1-\alpha) y_{t}}{h_{t}} \\
\frac{1}{c_{t}}\left(1+\tau_{x t}\right)(1+\gamma)=E_{t} \frac{\beta}{c_{t+1}}\left[\alpha \frac{y_{t+1}}{k_{t+1}}+\left(1+\tau_{x t+1}\right)(1-\delta)\right] \\
y_{t}=k_{t}^{\alpha}\left(z_{t} h_{t}\right)^{1-\alpha} \\
y_{t}=c_{t}+x_{t}+g_{t} .
\end{gathered}
$$

Equation (1) displays the intratemporal leisure-consumption trade off. Equation (2) is the consumption Euler equation. Equations (3) and (4) are the production function and the resource constraint faced by the economy. The variable $g_{t}$ is the 
government consumption wedge. It will be measured as the sum of per capita government spending plus net export.

\begin{tabular}{|l|l|l|l|l|l|}
\hline \multicolumn{7}{|c|}{ Table 1 Calibration } \\
\hline$\alpha$ & $\beta$ & $\gamma$ & $\delta$ & $n$ & $\theta$ \\
\hline 0.3 & 0.98 & 0.0229 & 0.05 & 0.0184 & 2.12 \\
\hline
\end{tabular}

\subsection{Accounting for wedges}

We apply the accounting procedure to the U.S. economy for 1889 to 1913 which contains two major business cycle episodes: the depression of the 1890s and the 1907 recessions. We first derive the series of the four wedges and then feed them back into the prototype growth model to assess the relative contributions of each wedge, or combinations thereof, to the observed fluctuations of output, labor, investment and consumption. As the primary source of data we use are Kendrick (1961) and Balke and Gordon (1986); a detailed data description is placed into the Appendix. ${ }^{5}$ These sources offer annual time series of aggregate output, labor, consumption and investment. The data of investment consists of gross private domestic investment, consumption durable and net factor payments. The capital stock is constructed using the perpetual inventory method. Computing requires one value of capital. We set $k_{1892}$ as this initial capital by setting it such that the capital-output ratio in 1892 matches the average capital-output ratios during 1889-1913. Then we generate a time series of the capital stock using the capital accumulation equation. In line with the artificial economy, all relevant data is converted into per capita variables (by using population) and is adjusted by the long-run productivity growth rate $\gamma$ (except for labor) to render them stationary. Population data is obtained from the Historical Statistics of the United States

\footnotetext{
${ }^{5}$ We acknowledge the data constructed by Gallman (1966) and Romer (1989). We faced a tradeoff between using their qualitativly better series for aggregate output (but not covering all series required for the accounting) and using data that is likely of lower quality but internally consistent and covering all variables that we need. In the end, we decided to use the Kendrick, Balke and Gordon source.
} 
(2006). Lastly, $\gamma$ is set to be $2.29 \%$, which is based on a peak-to-peak measure from 1889-1913.

\subsubsection{Measuring the wedges}

Three wedges are straightforward to compute. Given data for capital, labor and output, the efficiency wedge is computed from the firm's production function (3) and it shows up in the prototype model as aggregate total factor productivity. From equation (1) we can obtain the labor wedge. The investment wedge $1 /\left(1+\tau_{x t}\right)$ is not directly observable because it is captured by the Euler equation which involves agents' expectations. It is therefore necessary to estimate the stochastic process of the wedges to obtain optimal decision rules. The procedure is described in the Appendix and in detail in Chari et al. (2007). We calibrate various parameters to values familiar from the (real) business cycle literature. The capital share $\alpha$ equals 0.3 , the annual depreciation rate $\delta$ is five percent. The annual discount factor $\beta$ and the time allocation parameter $\theta$ are set that the balanced growth path of the artificial economy matches the measured economy's 1889-1913 average capital-output and the consumption-output ratio. The choice also pins steady state hours worked. The population growth $n$ is 1.84 percent which is the average population growth rate over the period 1889-1913. Table 1 summarizes the calibrations of the parameters. With these parameter values assigned, we can obtain the process governing the stochastic wedges and then derive the realized value of the investment wedge.

The labor wedge describes the gap between the firm's marginal product of labor and the household's marginal rate of substitution. For example, economies with sticky prices produce a labor wedge (Chari et al. 2007). The government consumption wedge involves international borrowing and lending and derives directly from equation (4). The investment wedge captures frictions distorting the intertemporal Euler equation. For example, Bernanke et al. (1999) depict that models with 
credit market frictions can be reconstructed as the prototype model with investment wedges. However, not all financial frictions reflect in the investment wedge. Chari et al. (2007) provide an example of a input-financing friction model to demonstrate that financial distortions may also manifest itself as efficiency wedges rather than the investment wedge of the prototype model. Likewise, Brinca et al. (2016) show how Buera and Moll's (2015) model of financial imperfections translates into a mix of efficiency and labor wedges.

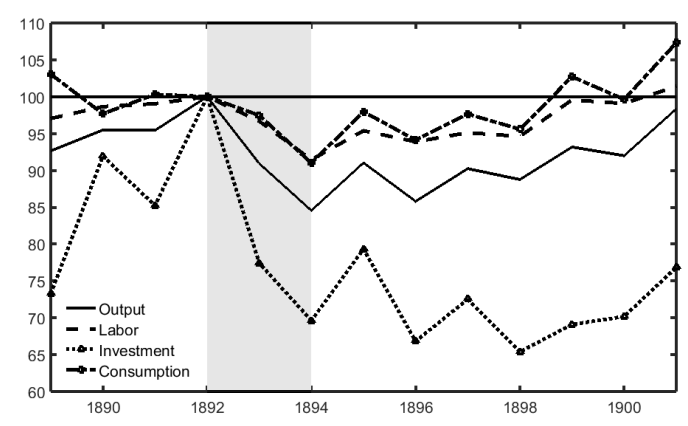

Figure 2: US Output, labor, investment and consumption 1889-1901.

\section{Results from accounting}

Our objective is to evaluate the importance for macroeconomic aggregates of the four wedges. By construction, we can exactly replicate the data if we feed in all of the four wedges jointly. By feeding only one wedge or combinations of wedges into the benchmark model, on the other hand, each of the wedge's contributions to the fluctuations in output, labor, investment and consumption can be traced. This section continues by first reporting the realized wedges before conducting the counterfactuals. 


\subsection{The Depression of the Nineties}

To begin with, Figure 2 plots the paths of detrended output, labor, investment and consumption for the U.S. over the period 1889-1901. All variables are normalized to equal 100 in 1892. The first economic contraction begins in the beginning of 1893 and reaches a trough the following year. In these two years output drops by over 15 percent relative to its trend. The economy then recovers until it contracts again. In fact, not until 1907 does the economy return back to trend (see also White, 1982). Hours, investment and consumption undergo similar patterns. Hours drop nine percent below their 1892 level in 1894. Investment declines by more than 28 percent and stays depressed past 1901. Hoffman (1956) points out that the long duration of low investment activities in wide areas of the economy such as railroads were significant factors shaping the depression and attributed to the tepid recovery. Consumption drops nine percent below its 1892 level. It returns rather quickly to trend and given that consumption is a good barometer for people's expectations (of future income) this fact suggests that a slow recovery a lower steady-state growth path - was not, as least initially, seen as a possibility.

\begin{tabular}{|l|l|l|}
\hline \multicolumn{3}{|l|}{ Table 2 Wedges 1889-1901 } \\
\hline Wedge & Std. dev. & Correlation \\
\hline Efficiency & 0.79 & 0.74 \\
\hline Labor & 1.05 & 0.54 \\
\hline Investment & 1.43 & -0.18 \\
\hline Government & 4.74 & -0.10 \\
\hline
\end{tabular}

Figure 3 graphs the realizations of the four wedges. The efficiency wedge falls dramatically between 1892 and 1894, followed by another slump in 1895. The labor wedge slightly increases in 1893, but it falls sharply in 1894. Table 2 summarizes standard statistics of the four wedges relative to output including cross correlations. Overall, the efficiency wedge and the labor wedge display strong positive correlations with output at 0.74 and 0.54 . The investment wedge and government wedge are negatively correlated with outputs. This result parallels Chari et al.'s 
(2002) findings that distortions associated with investment wedges diminished in the Great Depression. This does not imply that financial frictions were not important but rather that they manifested themselves in other wedges. The little role played by the government wedge does not come unsurprising given the small share of the economy in the nineteenth and early twentieth century. Overall, this pattern points to only two of the wedges playing an important role for the Nineties.
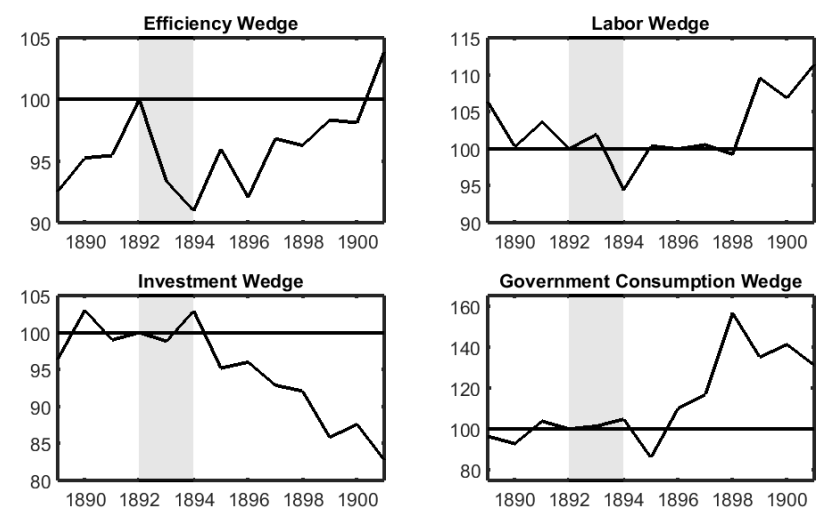

Figure 3: Measured wedges, 1889-1901.
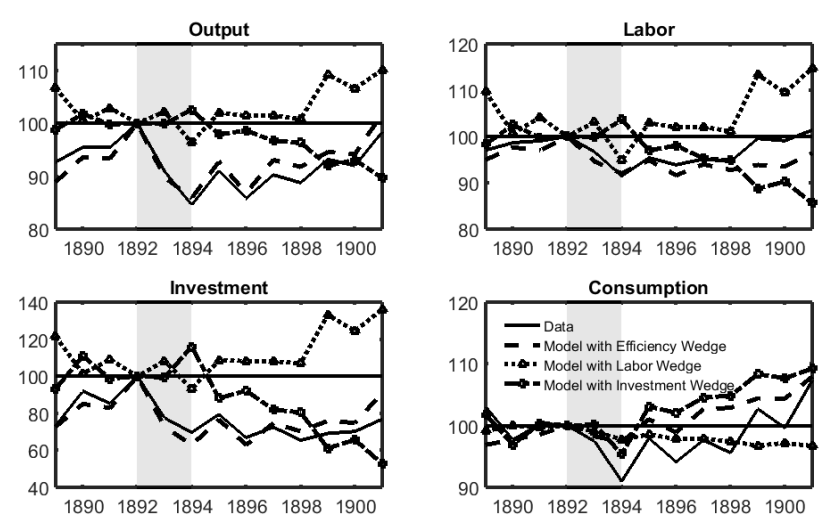

Figure 4: Decomposition 1889-1901.

We continue with counterfactual exercises. Figure 4 compares historical with 
simulated data when introducing one wedge at a time. ${ }^{6}$ You will notice the remarkable coincidence of the time path of U.S. aggregate output and the simulated model when driven by the efficiency wedge only. The efficiency wedge is also important in explaining the movements of investment, although it generates too excessive of a slump after 1892 to 1894 and it slightly overpredicts the recovery after 1897. The role of the labor wedge appears to be less important for output but its contribution to employment, especially post-1894, is essential. The other wedges are less important.

\begin{tabular}{|l|l|l|}
\hline \multicolumn{3}{|l|}{ Table 3 Wedges 1901-1913 } \\
\hline Wedge & Std. dev. & Correlation \\
\hline Efficiency & 0.74 & 0.98 \\
\hline Labor & 0.67 & -0.16 \\
\hline Investment & 0.48 & 0.09 \\
\hline Government & 2.24 & 0.05 \\
\hline
\end{tabular}

\subsection{The 1907 recession}

We then apply the same accounting procedure to the 1901 to 1913 period. We set 1906 as the base year in the graphs. In Figure 5, you will see that data output decreases by more than 14 percent from 1906 to 1908. At the same time, labor and investment fall drastically as well. The recession is followed by a swift but incomplete recovery and output still hovers around eleven percent below peak in 1913. Figure 6 graphs the wedges and in Table 3 we show several summaries of these wedges. The contemporaneous cross correlation of the efficiency wedge with output is 0.98 while the labor, investment and government consumption wedges show hardly any such correlation with aggregate activity. These results suggest that the efficiency wedge again plays a most significant role relative to the other wedges. The decomposition results for the period are in Figure 7. The upshot is similar to that of the Nineties.

\footnotetext{
${ }^{6}$ We do not report the results for the government wedge since in our samples, as well as in most BCA studies on the US, it does not explain macro fluctuations.
} 


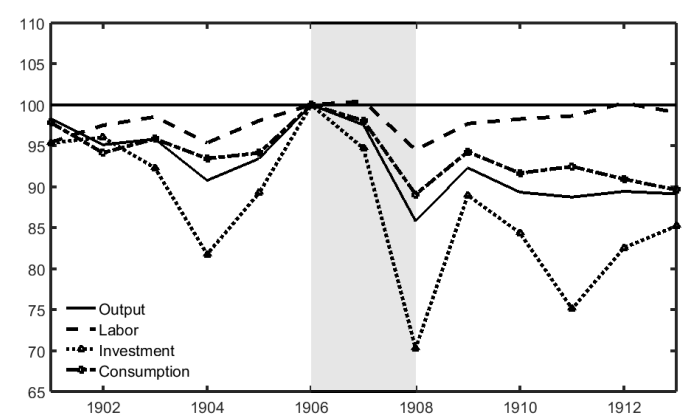

Figure 5: US Output, labor, investment and consumption 1901-1913.
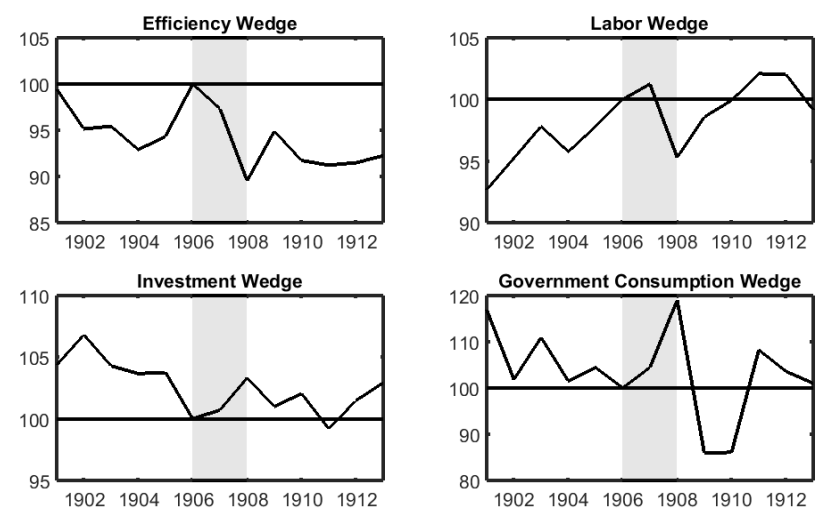

Figure 6: Measured Wedges 1901-1913.

Table 4 shows the fall of U.S. output during the recession years as well as the artificial series: the efficiency wedge accounts for the most of the output declines. Thus, the key message that comes out of the analysis so far is that we need to come up with a way to account for the efficiency and, to some extend, labor wedges.

\begin{tabular}{|l|l|l|}
\hline \multicolumn{3}{|l|}{ Table 4 Contribution to output decline } \\
\hline Variable & $1892-1894$ & $1906-1908$ \\
\hline U.S. & -15.4 & -14.2 \\
\hline Efficiency & -14.1 & -15.9 \\
\hline Labor & -3.6 & -1.5 \\
\hline Investment & 2.6 & 3.0 \\
\hline Government & 0.2 & 0.6 \\
\hline
\end{tabular}



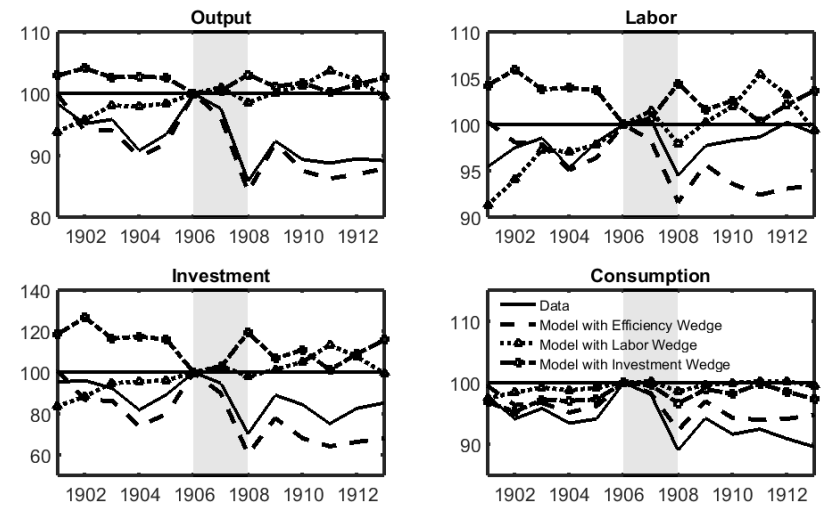

Figure 7: Decomposition 1901-1913.

\subsection{A note on robustness}

The measured wedges remain robust with respect to changes in the calibration. For example, we increased the steady state hours worked by 20 percent by resetting the preference parameter $\theta$. Then, a such newly-computed efficiency wedge, the friction that played a most prominent role in our analysis, is correlated with the benchmark wedge at 0.98 and 0.99 for the 1889-1901 and 1901-1913 periods. Recalculating the labor wedge has a similarly small effect. Another way to look at this would be comparing counterfactual output series when driven by, say, the labor wedge only. We find that both wedges generate aggregate output series that are correlated at 0.99 for the 1889-1913 period. Similarly, we experimented with different measures of the capital stock. Again, and due to its slow moving pattern, the impact remains negligibly small. ${ }^{7}$

\section{Discussion}

The findings in the previous section highlight the importance of the efficiency and labor wedges to economic fluctuations during the pre-Fed episode. Business

\footnotetext{
${ }^{7}$ We provide visualizations of these robustness exercises in the Appendix.
} 
cycle accounting does not identify the source of the shocks and it points to transmission mechanisms. In this section, we discuss various frictions that tie to these wedges during the Nineties' Depression and the 1907 recession.

\subsection{Understanding the efficiency wedge}

The efficiency wedge captures variations in the effectiveness of factor inputs to produce output and thus this wedge is conceptually like total factor productivity. To begin with, we point to various attributes of the identified wedge series that classify it as operating like supply shocks. Field (2010) documents a procyclical behavior of total factor productivity in the U.S. for over a century. This pattern also shows for the efficiency wedge during the 1890-1913 period. We regress Weir's (1992) unemployment data on the wedge and we find a negative coefficient (standard errors in parentheses, Huber-White covariance method)

$$
\Delta \ln z_{t}=\underset{(0.01)}{0.002}-\underset{(0.01)}{0.02} \Delta U R_{t} \quad R^{2}=0.58
$$

thus, a result reminiscent of Field's. One of the observable implications, stressed for example by Cooley and Ohanian (1991), of real business cycle theory is that an increase in total factor productivities of firms drives down costs and the price level. ${ }^{8}$ We find a similar, albeit statistically weak, nexus of the efficiency wedge and inflation

$$
\Delta \ln z_{t}=\underset{(0.01)}{0.003}-\underset{(0.11)}{0.119} \Delta \ln C P I_{t} \quad R^{2}=0.04
$$

Moreover, in every year after the efficiency wedge reaches a peak, inflation increases (by eight, two, four percent). In all these inflationary years (1893, 1902 and 1907), the economy slid into a slump. Finally, the efficiency wedge closely tracks labor productivity as you can see in Figure 8. Thus, conceptually the wedge fits the supply side view. Yet, and this is one of BCA's main insights, fluctuations in the

\footnotetext{
${ }^{8}$ Annual inflation as measured by the CPI averaged at less than one percent between 1889 and 1913.
} 
wedges can arise from various frictions and we now discuss possible interpretations of the efficiency wedge.
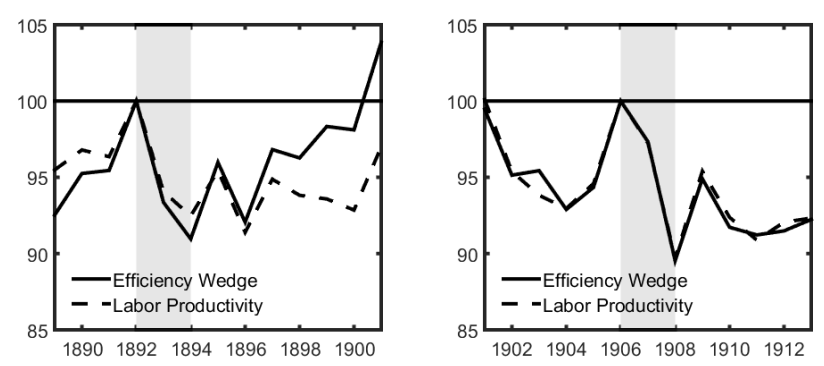

Figure 8: Efficiency wedge and labor productivity.

Here, we are led by previous discussions of this wedge that point to financial frictions, trade frictions and also consider measurements of inputs coming from variations in capital utilization. In fact, Fels (1959) describes a role of the last in terms of excess capacity and reorganization activities that explain the tepid recovery from the 1893 slump. In our benchmark model, the efficiency wedge treats capital utilization rate as constant over time. It is the naive measure of Solow residuals. Clearly, capital utilization varies significantly over the cycle. For example, Harrison and Weder's (2009) exploration into the Roaring Twenties stresses that procyclical capital utilization could be an important transmission mechanism, motivated by empirical findings by Bresnahan and Raff (1991). ${ }^{9}$ This insight implies that the Solow residual measure of production efficiency tends to overstate aggregate productivity fluctuations. Thus, it is necessary to isolate the effect of variable capital utilization from the efficiency wedge if one aims to understand its "true"behavior and the frictions that captured the wedge. Take a production function of the form

$$
y_{t}=\left(u_{t} k_{t}\right)^{\alpha}\left(A_{t} h_{t}\right)^{1-\alpha}
$$

in which $u_{t}$ denotes the capital stock's utilization rate and $A_{t}$ measures the uti-

${ }^{9}$ See also Burnside et al. (1995). 
lization adjusted productivity. To limit utilization from going to infinity, physical capital depreciation depends on utilization as follows

$$
(1+\gamma)(1+n) k_{t+1}=\left(1-\frac{1}{\varphi} u_{t}^{\varphi}\right) k_{t}+x_{t} \quad \varphi>1
$$

As capital utilization data is not available for the period, we follow Harrison and Weder (2009) and compute a series of that is model-consistent. From the first-order condition for utilization

$$
u_{t}^{\varphi}=\alpha \frac{y_{t}}{k_{t}}
$$

we then derive a series for $\left\{u_{t}\right\}$ as data on both right-hand variables, namely output and the capital stock are available. ${ }^{10} \varphi$ refers to the elasticity of depreciation with respect to capital utilization and the steady state condition

$$
\varphi=\frac{(1+\gamma)-\beta(1-\delta)}{\beta \delta}
$$

pins it down. A series of the new wedge can be calculated from

$$
A_{t}^{1-\alpha}=\frac{y_{t}}{\left(u_{t} k_{t}\right)^{\alpha} h_{t}^{1-\alpha}} .
$$
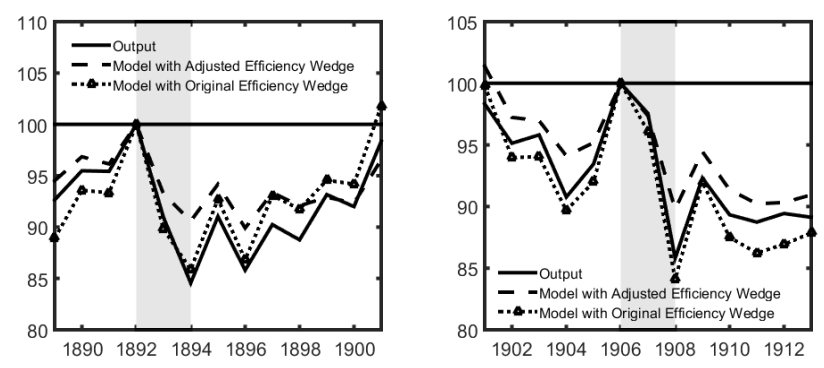

Figure 9: The effect of capital utilization.

Figure 9 plots artificial output when shocking the model with the utilization adjusted wedge and the original efficiency wedge, and U.S. data. The patterns of

\footnotetext{
${ }^{10}$ Harrison and Weder (2009) take capital utilization data from the BEA and compare it to such constructed series. They conclude that their method returns a good match.
} 
these series are very similar except that the adjusted wedge quite naturally accounts for smaller output declines, indicating to us that factor hoarding amplifies the role of the wedge. ${ }^{11}$ We infer that variable capital utilization produces some fluctuations in the efficiency wedge. However, these fluctuations are endogenous and not the primary factors that cause changes in aggregate activity. Both recessions were associated with banking panics (Wicker, 2000) and business failures closely associated with the worsening of financial situations (Fels, 1959). Failures of the National Cordage Company and insolvency in the railway industry led to stock market panic. The developments struck banks with force by bringing on pessimism and bank runs while causing declines in the money supply. In particular, the mix of industrialization and urbanization had created investment opportunities in railroad between 1870 and $1890 .{ }^{12}$ There are reasons to believe that investors flowed into this market and borrowed excessively relying on easy credit. Eventually, this situation led to a over-expanding of railroads which dried up the capital streams, continuing as business failures and bank suspensions (Hoffmann, 1956, Whitten, 2001). Such financial problems occurred again in 1907: bank runs and panics were triggered after the announcement that the National Bank of Commerce would not act as a clearing agent for Knickerbocker Trust Company. In both recessions financial eruptions caused credit to freeze up and therefore forced firms to cut planned capital investment and production.

That is, we link constraints to borrowing to resource misallocation across firms in particular as laid out by Hsieh and Klenow (2009) and Moll (2014). First, Bernanke $(1983,1995)$ points out that banking panics lead to an increase in the currency-deposit ratio which relates negatively with the money multiplier. Second, interest rate spreads can be regarded as a most basic concept of a financial disturbance as they reflect agency frictions within firms and financial intermedi-

\footnotetext{
${ }^{11}$ This is consistent with Chari et al. (2007), Klein and Otsu (2013) who find that the variable capital utilization specification downplays the importance of the efficiency wedge.

${ }^{12}$ See also Higgs (1971).
} 
aries (Hall, 2013). Now, during a financial crisis interest rate spreads open up and access to capital funding becomes constrained which prevents people and firms from generating optimal choices and thus induce production inefficiency. In fact, Chari et al. (2007) show how a detailed model with financial frictions modeled as input-financing frictions is equivalent to a prototype economy with only the efficiency wedge. Correspondingly, the discussion of the connection between the efficiency wedge and financial markets frictions continues in two ways. First, we walk through variations in financial lending from disruption in short-term lending rates, via bank suspensions and the money multiplier and, as repercussions in the real economy, instrumented by business failures. Second, we evaluate the role of financial frictions as in Bridji (2013), i.e., we redo the accounting procedure while replacing the efficiency wedge with the money multiplier.

As illustrated by Moen and Tallman (2018), the New York City call loan market played an important role in providing funding during our period of interest and in particular during episodes of crisis. Foremost, call loan rates indicate degrees of market tightness as, for example, changes of the monetary base and liquidity were only slow to eventuate as gold had to flow between countries. To sort out a connection to the efficiency wedge, we plot the call money interest rate around the wedge's three peaks 1892, 1901 and 1906. The Burns-Mitchell like diagram in Figure 10 shows that the two series displaying considerable comovement: after climbing slowly before the wedge (and the aggregate economy) reaches peaks, the interest rate takes flight thereafter. ${ }^{13}$ A similar connection can be picked up when, as Gorton (1988), Bernanke (1983) and Bridji (2013), we link bank panics and the effectiveness of the financial sector to changes in currency-deposit ratios. To this avail, Figure 11 shows the correspondence of the money multiplier and the efficiency wedge. The money multiplier is represented as the ratio of aggregate broad money M2 over base money M0 and its correlation with the wedge is 0.57 .

\footnotetext{
${ }^{13}$ An analog pattern shows for Shiller's (2005) real one year interest rate.
} 
These disruptions to the workings of financial markets are related to the events of bank suspensions. ${ }^{14}$. Figure 12 demonstrates that they are highly correlated with the wedge at -0.66 . Lastly, and moving on to the consequences of the credit allocation process, we ask what is the relation of business breakdowns and the efficiency wedge. Figure 13 displays how the business failure rate (per listed enterprises) is related to the wedge. The correlation is -0.71 . All these financial variables point into the same direction: there is plausible comovement with the efficiency wedge.

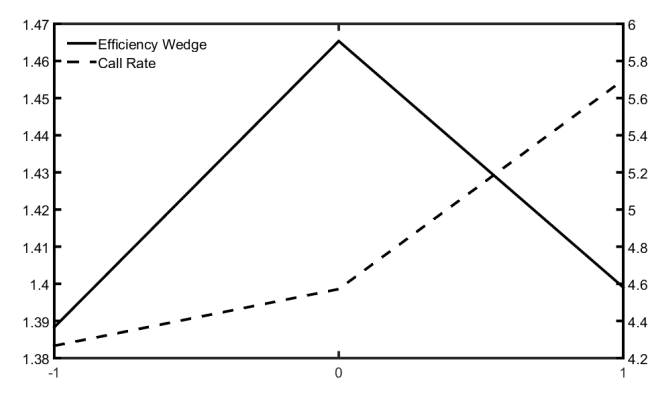

Figure 10: Efficiency wedge and New York City call loan market rate.
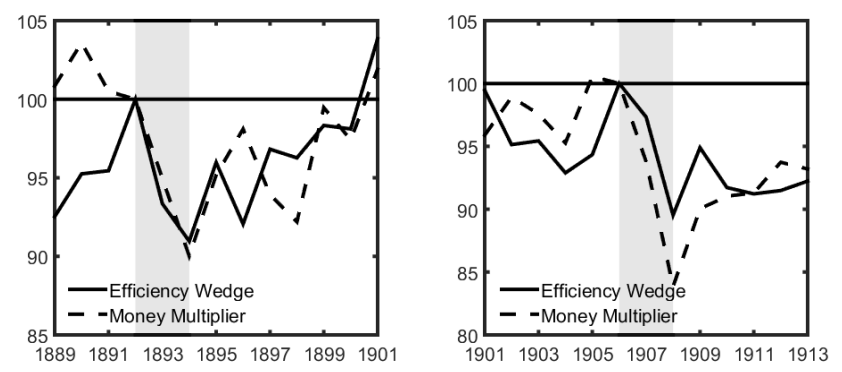

Figure 11: Efficiency wedge and the money multiplier.

To further investigate the role of financial frictions, we take up from Bridji (2013) who suggests to redo the accounting while replacing the efficiency wedge

\footnotetext{
${ }^{14}$ Dun's Review data begins in second half of 1893.
} 


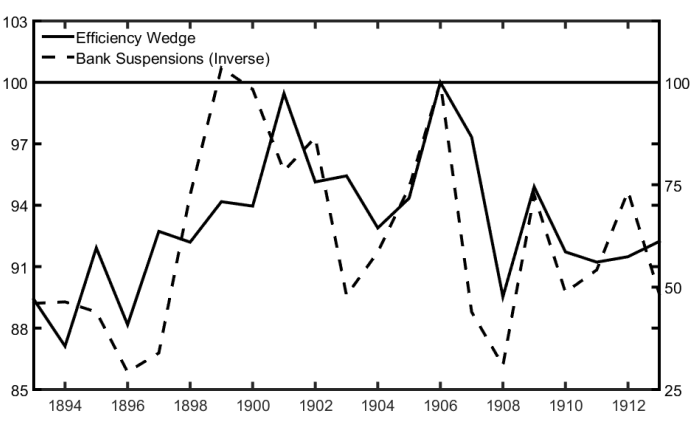

Figure 12: Efficiency wedge and bank suspensions.
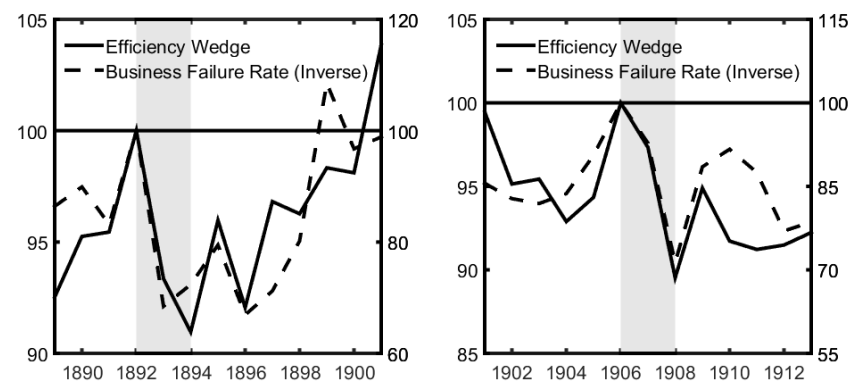

Figure 13: Efficiency wedge and business failures.

with, for example, the money multiplier. As seen above, the relationship between the money multiplier and the efficiency wedge is a positive. We evaluate the role of money multiplier on output by replacing the efficiency wedge by the money multiplier and redo feed it back into the model. The effects of the financial variable on output are shown in Figure 14. Counterfactual output again well replicates the aggregate business cycle. In sum, these results suggest that future work should focus on financial frictions that translate into changes of the efficiency wedge when studying the Depression of 1890s and the recession of 1907. 

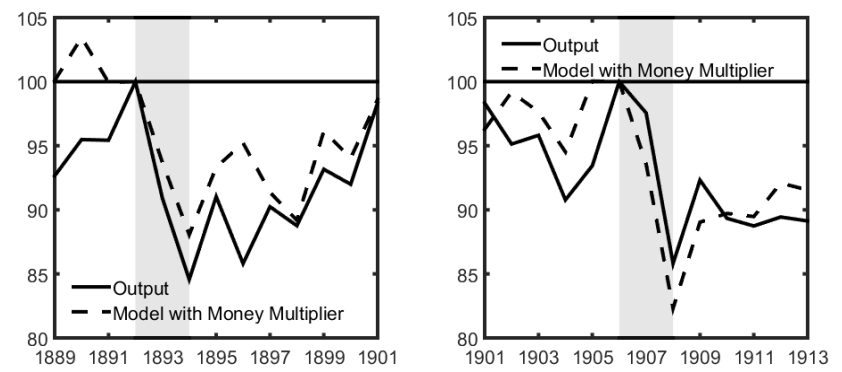

Figure 14: Aggregate output: data versus simulated model (money multiplier).

\begin{tabular}{llllll}
\hline \multicolumn{2}{l}{ Table 5 Second moments } & $1889-1913$ \\
Variable & Std. dev. & \multicolumn{5}{c}{ Cross correlations } \\
\cline { 3 - 6 } & & Output & Labor wedge & Wage markup & Price markup \\
\hline Output & 4.24 & 1 & & & \\
Labor wedge & 9.05 & 0.17 & 1 & 1 & \\
Wage markup & 12.10 & -0.28 & -0.96 & -0.93 & 1 \\
Price markup & 5.56 & 0.31 & 0.81 & &
\end{tabular}

\subsection{Understanding the labor wedge}

We consider two theories that can explain movements in the labor wedge. First, the most obvious interpretation for the reduction of the labor wedge should be a rise of labor or consumption taxes, as they directly affect consumer's decision about the time allocation and, thus, labor supply (Ohanian, 2009). To determine whether these taxes were responsible for the deterioration of the labor wedge, we use the exercise tax as the proxy of the consumption tax. ${ }^{15}$ Figure 15 plots the labor wedge and the inverse of consumption tax. The two variables apparently do not follow the same patterns and the tax does not provide explanation.

Second, the labor wedge can be understood as the gap between the firm's marginal product of labor (MPL) and the household's marginal rate of substitution (MRS). Gali et al. (2007) and Karabarbounis (2014) decompose the gap it into

\footnotetext{
${ }^{15}$ Federal income taxation was not impose until the 16th Amendment (1913).
} 

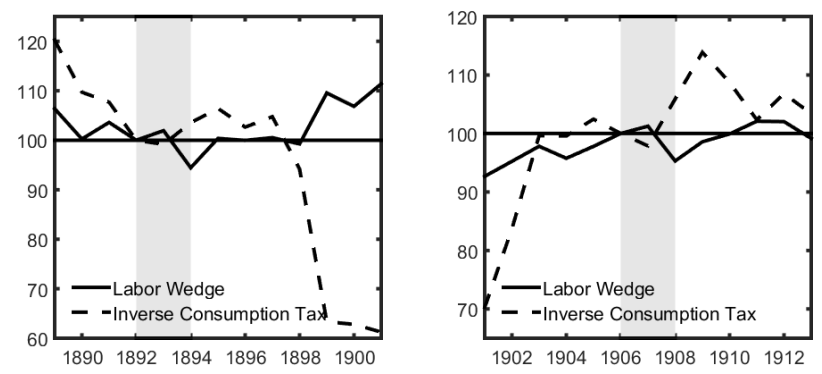

Figure 15: Labor wedge and tax.

two components: the wage markup and the price markup. ${ }^{16}$ The wage markup represents the supply side of the wedge: it comprises of the gap between the real wage and the MRS. The price markup stands for frictions on the labor demand side: it is the gap between the MPL and the real wage. Both markups distort the labor market. ${ }^{17}$ Table 5 provides summary statistics for output, the labor wedge and the two markups over the period of 1889 to 1913 . The wage markup is negatively correlated with the labor wedge at -0.96 , thus indicating that the wage markup explains the most variations of the labor wedge. Figure 16 plots the time series of the real wage (manufacturing industries) and the MRS over the two sample periods. The real wage is approximately 13 and eight percent above the MRS in 1894 and 1908, implying substantial wage markups. This parallels Fels' (1959) descriptions of labor troubles having caused parts of the contraction. Also, there is evidence for nominal wage stickiness for have caused frictions captured by the wage markup. This fact is also reported by Hanes (1993) who points to a decrease in wage flexibility caused by larger bargaining power of workers. Likewise, Sundstrom (1992) stresses workers' resistance to reduce nominal wages was the culprit of the sluggishness of wage adjustment in the 1892-1894 recession. In Figure 16 you can observe the opening of a considerable gap between the real

\footnotetext{
${ }^{16}$ See Weder (2006) for an alternative explanation.

${ }^{17}$ We construct series of model-consistent MPL and MRS using historical data.
} 
wage and the MRS after 1893. However, the gap flipped after 1899 and this suggest a role for the price markup for the last recession of the 1890s. During the period of 1901 to 1913, the picture is somewhat muddled. Real wages persistently trended downward with prices moving upward at the same time - resulting from increasing gold stock (Friedman and Schwartz, 1963). This pattern again suggests nominal wage stickiness.
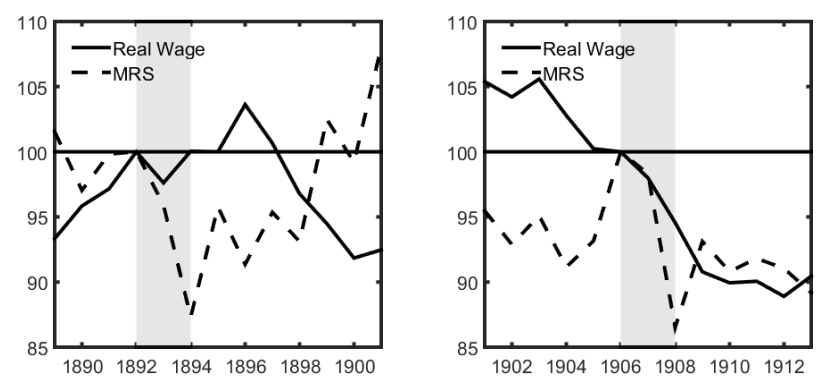

Figure 16: Real wage and MRS.

\section{Conclusion}

We conduct a Business Cycle Accounting exercise on historical United States recessionary episodes to put our finger on the underlying forces responsible for aggregate fluctuations, particularly the 1893 and 1907 recessions. This method helps isolating promising classes of models to better understand data. Our findings suggest that the efficiency wedge accounts for the bulk of the fluctuations in output and also in investment. The labor wedge played a less important role while the other two wedges can be interpreted as mostly irrelevant. What do we learn from this result? This finding implies that models that emphasize fluctuations in the investment or government wedges are less promising than those that emphasize fluctuations in the efficiency and labor wedges. Phrased alternatively, models attempting to replicate and explain the economic patterns of this period should 
put at center stage market frictions that manifest themselves as in the prototype model's two wedges. We also provide some thoughts on potential explanations of the two wedges. Here, financial market frictions appear to be best candidates that explain variations of the efficiency wedge. To understand the movements of the labor wedge, focus should be put onto the supply side of the labor market, that is, the gap between the marginal rate of substitution and real wages. 


\section{References}

[1] Balke, N. and R. Gordon (1986): "Historical Data", The American Business Cycle: Continuity and change, University of Chicago Press, 781-850.

[2] Bernanke, B. (1983): "Non-monetary Effects of the Financial Crisis in the Propagation of the Great Depression", American Economic Review 73, 257276.

[3] Bernanke, B. (1995): "The Macroeconomics of the Great Depression: a comparative approach", Journal of Money, Credit, and Banking 27, 1-28.

[4] Bernanke, B., M. Gertler and S. Gilchrist (1999) "The Financial Accelerator in a Quantitative Business Cycle Framework", Handbook of Macroeconomics 1, Elsevier, 1341-1393.

[5] Bresnahan, T. and D. Raff (1991): "Intra-industry Heterogeneity and the Great Depression: the American motor vehicles industry 1929-1935", Journal of Economic History 51, 317-331.

[6] Bridji, S. (2013): "The French Great Depression: A business cycle accounting analysis", Explorations in Economic History 50, 427-445.

[7] Brinca, P., V. Chari, P. Kehoe and E. McGrattan (2016): "Accounting for Business Cycles", Handbook of Macroeconomics 2A, Elsevier, 1013-1063.

[8] Buera, F. and B. Moll (2015): "Aggregate Implications of a Credit Crunch: The importance of heterogeneity", American Economic Journal: Macroeconomics 7, 1-42.

[9] Burnside, C., M. Eichenbaum and S. Rebelo (1995): "Capital Utilization and Returns to Scale", NBER Macroeconomics Annual 10, 67-110. 
[10] Carter, S., S. Gartner, M. Haines, A. Olmstead, R. Sutch and G. Wright (2006): Historical Statistics of the United States: Earliest times to the present, Cambridge University Press.

[11] Chari, , V., P. Kehoe and E. McGrattan (2002): "Accounting for the Great Depression", American Economic Review 92, 22-27.

[12] Chari, V., P. Kehoe and E. McGrattan (2007): "Business Cycle Accounting", Econometrica 75, 781-836.

[13] Cooley, T. and L. Ohanian (1991): "The Cyclical Behavior of Prices", Journal of Monetary Economics 28, 25-60.

[14] Fels, R. (1959): American Business Cycles 1865-1897, University of North Carolina Press.

[15] Field, A. (2010): "The Procyclical Behavior of Total Factor Productivity in the United States, 1890-2004", Journal of Economic History 70, 326-350.

[16] Friedman, M. and A. Schwartz (1963): A Monetary History of the United States, 186r-1960, Princeton University Press.

[17] Gali, J., M. Gertler and J. Lopez-Salido (2007): "Markups, Gaps, and the Welfare Costs of Business Fluctuations", Review of Economics and Statistics 89, 44-59.

[18] Gallman, R. (1966): "Gross National Product in the United States, 18341909", in Output, Employment, and Productivity in the United States after 1800, edited by D. Brady, NBER, 3-90.

[19] Glasner, D., T. Cooley and L. Murphy (1997): Business Cycles and Depressions: An encyclopedia, Taylor \& Francis. 
[20] Gorton, G. (1988): "Banking Panics and Business Cycles", Oxford Economic Papers 40, 751-781.

[21] Gorton, G. and E. Tallman (2018): Fighting Financial Crises: Learning from the Past, University of Chicago Press.

[22] Hall, R. (2013): "Financial Frictions", International Journal of Central Banking 9, 155-163.

[23] Hanes, C. (1993): "The Development of Nominal Wage Rigidity in the Late 19th Century", American Economic Review 83, 732-56.

[24] Harrison, S. and M. Weder (2009): "Technological Change and the Roaring Twenties: a neoclassical perspective", Journal of Macroeconomics 31, 363375.

[25] Higgs, R. (1971): The Transformation of the American Economy 1865-1914, John Wiley \& Sons.

[26] Hoffmann, C. (1956): "The Depression of the Nineties", Journal of Economic History 16, 137-164.

[27] Hoffmann, C. (1970): The Depression of the Nineties, Greenwood Publishing.

[28] Hsieh, C. and P. Klenow (2009): "Misallocation and Manufacturing TFP in China and India", Quarterly Journal of Economics 124, 1403-1448.

[29] Karabarbounis, L. (2014): "The Labor Wedge: MRS vs. MPN", Review of Economic Dynamics 17, 206-223.

[30] Kehoe, T. and E. Prescott (2008): "Using the General Equilibrium Growth Model to Study Great Depressions: A reply to Temin", Federal Reserve Bank of Minneapolis Staff Report 418. 
[31] Kendrick, J. (1961): Productivity Trends in the United States, Princeton University Press.

[32] Klein, A. and K. Otsu (2013): "Efficiency, Distortions and Factor Utilization during the Interwar Period", University of Kent mimeo.

[33] Lebergott, S. (1964): Manpower in Economic Growth, McGraw-Hill.

[34] Moen, R. and E. Tallman (2018): "The Transmission of the Financial Crisis in 1907: an empirical investigation", Cliometrica 12, 277-312.

[35] Moll, B. (2014): "Productivity Losses from Financial Frictions: Can selffinancing undo capital misallocation?", American Economic Review 104, 3186-3221.

[36] Nason, J. and E. Tallman (2015): "Business Cycles And Financial Crises: The Roles Of Credit Supply And Demand Shocks," Macroeconomic Dynamics 19, 836-882.

[37] Ohanian, L. (2009): "Understanding Economic Crises: The Great Depression and the 2008 Recession", Economic Record 86, 2-6

[38] Pensieroso, L. (2011): "The Great Depression in Belgium from a Neoclassical Perspective", Review of Economic Dynamics 14, 389-402.

[39] Romer, C. (1989): “The Prewar Business Cycle Reconsidered: New Estimates of Gross National Product, 1869-1908", Journal of Political Economy 97, 137.

[40] Shiller, R. (2005): Irrational Exuberance, Princeton University Press.

[41] Sundstrom, W. (1992): "Rigid Wages or Small Equilibrium Adjustments? Evidence from the contraction of 1893", Explorations in Economic History $29,430-455$. 
[42] Tallman, E. (2012): "The Panic of 1907", Federal Reserve Bank of Cleveland mimeo.

[43] Temin, P. (1998): "The Causes of American Business Cycles: an essay in economic historiography", NBER Working Paper 6692.

[44] Weder, M. (2006): "The Role of Preference Shocks and Capital Utilization in the Great Depression", International Economic Review 47, 1247-1268.

[45] Weir, D. (1992); "A Century of U.S. Unemployment, 1890-1990: Revised estimates and evidence for stabilization", Research in Economic History 14, $301-346$.

[46] White, G. (1982): The United States and the Problem of Recovery after 1893, University of Alabama Press.

[47] Whitten, D. (2001): "Depression of 1893", EH.Net Encyclopedia.

[48] Wicker, E. (2000): Banking Panics of the Gilded Age, Princeton University Press.

\section{Appendix}

This Appendix provides the details of source and construction of the data used in this paper. All data are annual and for the period 1889-1913 unless otherwise stated. We will begin by quickly outlining the BCA method of the shocks' estimation. Details can be found in Brinca et al. (2016).

\subsection{BCA}

Three wedges are straightforward to compute. Given data for capital, labor and output, the efficiency wedge is computed from the firm's production function (3) and it shows up in the prototype model as aggregate total factor productivity. 
From equation (1) we can obtain the labor wedge. The investment wedge $1 /(1+$ $\left.\tau_{x t}\right)$ is not directly observable because it is captured by the Euler equation which involves agents' expectations. It is therefore necessary to estimate the stochastic process of the wedges to obtain optimal decision rules. We follow Chari et al. (2007) and assume that all wedges follow first-order autoregressive processes

$$
s_{t+1}=P_{0}+P s_{t}+\varepsilon_{t+1}, \varepsilon_{t} \sim N\left(0_{4}, V\right)
$$

where

$$
s_{t}=\left[\log \left(z_{t}\right), \tau_{h t}, \tau_{x t}, \log \left(g_{t}\right)\right]^{\prime}
$$

and $\varepsilon_{t}$ is a vector of independently and identically distributed shocks across time with zero mean and covariance matrix $V$. These shocks are allowed to contemporaneously correlate across equations. We estimate $P_{0}, P$ and the lower triangular matrix $Q$ which is defined so that $V=Q Q^{\prime}$ using maximum likelihood. To do this, the prototype model is log-linearized around the steady state and the undetermined coefficients method is used. Then, the state-space form of the model is given by

$$
\begin{gathered}
X_{t+1}=A X_{t}+B \epsilon_{t+1} \\
Y_{t}=C X_{t}+\omega_{t}
\end{gathered}
$$

where

$$
X_{t}=\left[\log \left(k_{t}\right), \log \left(z_{t}\right), \tau_{h t}, \tau_{x t}, \log \left(g_{t}\right), 1\right]^{\prime}
$$

and

$$
Y_{t}=\left[\log \left(y_{t}\right), \log \left(x_{t}\right), \log \left(h_{t}\right), \log \left(g_{t}\right)\right]^{\prime} .
$$

The steady state value of the efficiency wedge, labor wedge and government consumption are the sample mean of their measured values over the period of 18891913. The steady state level of the investment wedge is given by

$$
\tau_{x}=\alpha \frac{y}{k} \frac{1}{\gamma / \beta-(1-\delta)}-1
$$


which is obtained from the steady state expression of the Euler equation. Here, we set $y / k$ to the average output-capital ratio over the 1889-1913 period. With these parameter values assigned, we can obtain the process governing the stochastic wedges and then derive the realized value of the investment wedge.

\subsection{A note on robustenss}

The measured wedges remain robust with respect to changes in the calibration. Below figures displays the impact on the efficiency wedge as well as on aggregate output. For example, we increased (reduced) the steady state hours worked by 20 percent by resetting the preference parameter $\theta$. Then, a such newly-computed efficiency wedge, the friction that played a most prominent role in our analysis, is correlated with the benchmark wedge at 0.98 and 0.99 for the 1889-1901 and 19011913 periods. Similarly, we experimented with different measures of the capital stock. Again, and due to its slow moving pattern, the impact remains negligibly small.
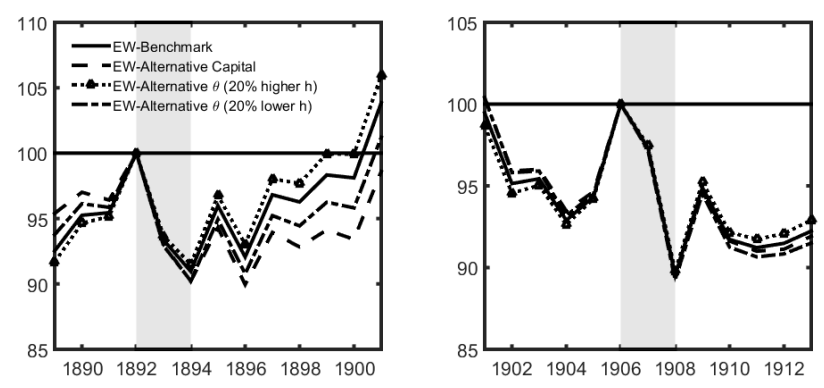

Figure 17: Robustness.

\subsection{Original Data}

O.1. Gross National Product, Commerce Concept. Millions of 1929 Dollars. Source: Kendrick (1961), P.290, Table A-IIa. 

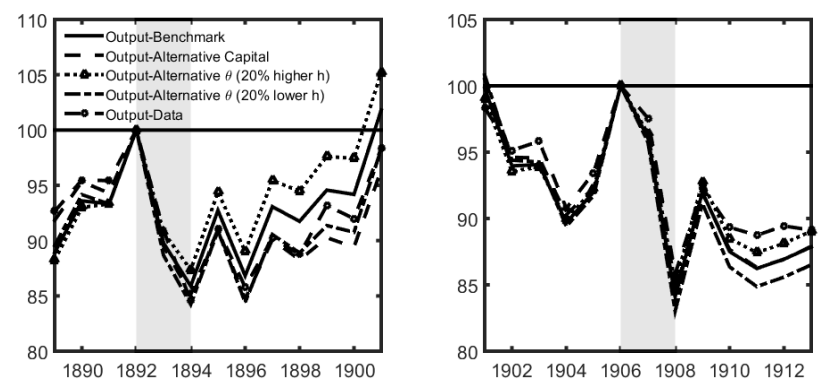

Figure 18: Robustness.

O.2. Gross National Product, Commerce Concept. Millions of Current Dollars. Source: Kendrick (1961), P.296, Table A-IIb.

O.3. Manhours, Total. Millions. Source: Kendrick (1961), P.311, Table A-X.

O.4. Total Consumption Expenditures, Commerce Concept. Billions of 1929 Dollars. Source: Kendrick (1961), P.290, Table A-IIa.

O.5. Gross Private Domestic Investment, Commerce Concept. Millions of 1929 Dollars. Source: Kendrick (1961). P.290, Table A-IIa.

O.6. Consumption Durable. Millions of Current Dollars. Source: Historical Statistics of the United States (2006), P.3-270, Series Cd411.

O.7. Resident Population, Total. Thousand. Source: Historical Statistics of the United States (2006), P.1-28, Series Aa7.

O.8. Yield on Corporate Bonds. Source: Balke and Gordon (1986), p.781, Table 1.

O.9. Commercial Paper Rate. Source: Balke and Gordon (1986), p.781, Table 1.

O.10. Exercise Taxes. Thousand Dollars. Source: Historical Statistics of the United States, Colonial Times to 1970, p.1108, Series 364-373.

O.11. Aggregate Broad Money M2, Friedman and Schwartz. Source: Historical Statistics of the United States (2006), P.3-604, Series Cj45.

O.12. High-Powered Money M0, Friedman and Schwartz. Source: Historical 
Statistics of the United States (2006), P.3-631, Series Cj141.

O.13. Ninety Day Time-Money Rates on Stock Exchange Loans for New York, converted to an annual data series by temporal averaging, FRED M13003US35620M156NNBR.

O.14. Long Government Bond Yield 10yr, www.econ.yale.edu/ shiller/data

O.15. Business Failure Rate (Failure rate per 10,000 listed enterprises). Source: Historical Statistics of the United States, Colonial Times to 1970, p.912, Series V 23.

O.16. Number of Suspended Banks for United States, FRED, Q09064USQ469NNBR.

\subsection{Constructed Data}

C.1. GNP Deflator=0.2./O.1.

C.2. Net Factor Payments $=0.005 \times 0.1$.

C.3. Real Per Capita Output=O.1./O.7./1000

C.4. Real Per Capita Investment=(O.5.+O.6./C.1.+C.2.)/O.7./1000

C.5. Real Per Capita Consumption $=($ O.4. $\times 1000-O .6 / C .1.) / O .7 . / 1000$

C.6. Per Capita Hours Worked=O.3./O.7./1000

C.7. Real Exercise Taxes=0.10./C.1.

C.8. Money Multiplier=O.12./O.11.

C.9. Real Wage=O.17./C.1. 